\title{
Patient outcome in migraine prophylaxis: the role of psychopharmacological agents
}

This article was published in the following Dove Press journal:

Patient Related Outcome Measures

16 September 2010

Number of times this article has been viewed

\author{
Maurizio Pompili ${ }^{1,2}$ \\ Gianluca Serafini' \\ Marco Innamorati' \\ Giulia Serra' \\ Giovanni Dominici' \\ Juliana Fortes-Lindau' \\ Monica Pastina' \\ Ludovica Telesforo' \\ David Lester ${ }^{3}$ \\ Paolo Girardi' \\ Roberto Tatarelli' \\ Paolo Martelletti ${ }^{4}$ \\ 'Department of Neurosciences, \\ Mental Health and Sensory \\ Functions, Suicide Prevention Center, \\ Sant'Andrea Hospital, Sapienza \\ University of Rome, Italy; ${ }^{2}$ McLean \\ Hospital - Harvard Medical School, \\ Boston, MA, USA; ${ }^{3}$ The Richard \\ Stockton College of New Jersey, \\ Pomona, NJ, USA; ${ }^{4}$ Department of \\ Medical and Molecular Sciences, 2nd \\ School of Medicine, Sant'Andrea \\ Hospital, "Sapienza" University of \\ Rome, Rome, Italy
}

Correspondence: Maurizio Pompili

Department of Neurosciences,

Mental Health and Sensory Functions,

University of Rome, Sant'Andrea Hospital,

Via Grottarossa 1037, Rome 00 189, Italy

$\mathrm{Tel}+390633775675$

$\mathrm{Fax}+390633775342$

Email maurizio.pompili@uniromal.it
Introduction: Migraine is a serious illness that needs correct treatment for acute attacks and, in addition, a treatment prophylaxis, since patients with migraine suffer during acute attacks and also between attacks.

Methods: A systematic review of the most relevant clinical trials of migraine headache and its epidemiology, pathophysiology, comorbidity, and prophylactic treatment (medical and nonmedical) was carried out using "Medline" and "PsychINFO" from 1973 to 2009. Approximately 110 trials met our inclusion criteria and were included in the current review. Results: The most effective pharmacological treatment for migraine prophylaxis is propranolol and anticonvulsants such as topiramate, valproic acid, and amitriptyline. Nonmedical treatments such as acupuncture, biofeedback, and melatonin have also been proposed. Peripheral neurostimulation has been suggested for the treatment of chronic daily headache that does not respond to prophylaxis and for the treatment of drug-resistant primary headache. The majority of the pharmacological agents available today have limited efficacy and may cause adverse effects incompatible with long-term use.

Limitations: The review was limited by the highly variable and often insufficient reporting of the complex outcome data and by the fact that migraine prophylaxis trials typically use headache diaries to monitor the course of the disease. The results of the different studies were also presented in different ways, making comparison of the results difficult.

Discussion: An adequate prophylaxis is crucial in reducing disability and preventing the evolution of the problem into a chronic progressive illness. The implications of the present findings were discussed.

Keywords: migraine, prophylaxis, pharmacological agents, nonmedical treatments, outcome

\section{Introduction}

Chronic daily headache is defined as a group of disorders in which headache occurs 15 or more days per month for at least 3 months. ${ }^{1}$ These disorders include: chronic migraine (which affects approximately $2.4 \%$ of the general population), ${ }^{2}$ migraine with or without aura and migraine aura without headache, chronic tension-type headache, hemicrania continua, and daily persistent headache. ${ }^{3}$

Migraine is usually a genetic disorder, often associated with other medical conditions such as depression (80\%), ${ }^{4}$ major depressive disorder, ${ }^{5,6}$ anxiety $(70 \%),{ }^{7}$ insomnia $(71 \%),{ }^{8}$ chronic fatigue $(66 \%),{ }^{9}$ and fibromyalgia $(35 \%) .{ }^{10}$

Factors such as stressful life events, contraceptive pill use, hypertension, mood changes, and the use or overuse of certain drugs may increase the frequency of headache, ${ }^{10}$ while dietary factors, regular sleep, physical activities, and relaxation 
technique are associated with a decrease in the frequency of headache. ${ }^{11}$ An untreated migraine attack may last from 4 to 72 hours. Often it is related to autonomic nervous system dysfunction and, in certain cases, it is associated with aura and can result in neurological symptoms. ${ }^{6}$ Migraine is a fluctuating disorder in which worsening and spontaneous improvements are common. ${ }^{12}$ In up to $25 \%$ of patients, pain may be preceded or accompanied by aura, which is usually characterized by visual disturbances, neurological events, fatigue, mood changes, and food cravings. The pain of migraine may be accompanied by phenomena such as photophobia, nausea, and vomiting. ${ }^{13}$ Studies conducted in Europe show that one out of five people are absent from work for 11 days or more due to migraine headache during any 3 -month period, and experience a $50 \%$ or more reduction in productivity or an inability to participate in social activities. ${ }^{14}$ It has been estimated that migraine is the most costly neurological disorder in Europe and one of the most costly in the United States. ${ }^{15,16}$ It has been estimated that the cost of migraine in Europe per patient is $€ 579$, or $€ 27$ billion for the 41 million patients aged between 18 and 65 years. $^{14}$

Migraine is an issue for both individuals and the society and causes reduced productivity at work and impaired family and social life. ${ }^{17}$ Early and accurate diagnosis is fundamental in optimizing treatment and in preventing progression. However, only a minority of migraine sufferers receive preventive treatment because of the cost. ${ }^{17,18}$ Additional problems for prophylactic medication involve the limited efficacy and the incidence of side effects of medications. ${ }^{5,19-21}$

The present paper analyzes the epidemiology and physiopathology of migraine, focusing on the need for and the efficacy of both medical and nonmedical therapeutic approaches for long-term preventive management of migraine and its role in patient outcome.

\section{Method}

A systematic review of the most relevant clinical trials about migraine headache and its epidemiology, physiopathology, comorbidity, and prophylactic treatment (medical and nonmedical) was carried out using "Medline, PsychINFO, Embase, Cinahl, and Pubmed databases" from 1973 to 2009 in order to maximize the chance of finding trials. We limited our research to articles in English, using as keywords the following terms: "migraine epidemiology," "migraine pathophisiology," "migraine comorbidity," "migraine treatment," "migraine prevention," "migraine AND disorders," "migraine AND prophylaxis," "migraine AND psychiatric disorders," and "migraine AND outcome". We included both open and double-blind trials. Trials exploring acute treatment for migraine were not included because we focused on long-term treatment of migraine.

The combined search strategies yielded 1,890 abstracts. After a complete analysis of the abstracts, 350 full-text articles were reviewed. Approximately 110 trials met our inclusion criteria and were included in the current review and 240 were excluded because they focused primarily on acute migraine and headache treatments, pharmacological approaches, or management in pediatric populations.

\section{Migraine: epidemiology and pathophysiology}

Migraine is a vascular headache characterized by periodic unilateral pulsating headaches associated with changes in the size of the arteries within and outside the brain. Several studies have demonstrated that the overall prevalence of migraine is $6 \%-8 \%$ for men and $15 \%-18 \%$ for women in Europe and America. ${ }^{18,22,23}$

Epidemiological data indicate that there are about 28 million patients suffering from migraine in the United States. ${ }^{24}$ The overall prevalence of migraine is roughly similar in industrialized countries. In a very recent study, Benamer, Deleu, and Grosset reported that the migraine prevalence was $2.6 \%-5 \%$ in Saudi Arabia and $7.9 \%$ in Qatar, while the 1-year migraine prevalence was $10.1 \%$ in Oman similar to that estimated worldwide. ${ }^{25}$ Migraine without aura is more common than is migraine with aura. In a Danish study of a representative sample of the general population, the lifetime prevalence of migraine with aura was $6 \%$, whereas the prevalence of migraine without aura was $9 \%$. Importantly, $1.2 \%$ of the population reported having both types of migraine. ${ }^{26}$

A migraine begins when hyperactive nerve cells send out impulses to the blood vessels, causing constriction, followed by the dilation of these vessels and the release of prostaglandins, serotonin, and other inflammatory substances that cause the pulsation to be painful. Cortical spreading depression (CSD) is a spontaneous neuronal depolarization moving slowly ( $3 \mathrm{~mm} / \mathrm{min})$ on the occipital cortex, which has a clinical counterpart in positive scotoma (a dark spot in the visual field) and teichopsia (transient visual sensations of bright shimmering colors). CSD activates the brainstem and gives rise to depolarization of ascending and 
descending pathways, perimeningeal vasodilatation and neurogenic inflammation. ${ }^{27,28}$ Therefore, in migraine, the excitatory events are believed to be proximal, whereas the neurovascular events that lead to pain production are distal. ${ }^{29}$ Repeated episodes of hyperexcitability could parallel, or cause, dysmodulation of nociceptive pathways, with a resultant chronic state, potential disease progression, and a refractoriness to therapy that some patients experience. ${ }^{27}$ Central sensitization, associated with abnormal neuronal excitability in the trigeminal nucleus caudalis, may also play a critical role in migraine pathogenesis, especially in the latter stages of an acute attack, and in the development of chronic forms of the disorder. ${ }^{30,31}$

Moskowitz suggested that some components of migraine pain are related to dural plasma protein extravasation with sterile neurogenic inflammation. ${ }^{32}$ Electrical stimulation of the trigeminal ganglion induces plasma protein extravasation which may be blocked by sumatriptan, a substance active in acute migraine attacks. ${ }^{33}$

However, a blockade of neurogenic plasma protein extravasation is not completely predictive of anti-migraine efficacy. ${ }^{34}$ Plasma protein extravasation may be an epiphenomenon rather than a pivotal mechanism of trigeminal activation and migraine generation. ${ }^{35}$

Migraine might be also explained by a dysfunction of neuromodulatory structures in the brainstem, such as the locus coeruleus or periaqueductal grey matter, which have a critical role in the regulation of cortical function and in modulating responses to afferent traffic. ${ }^{36}$

Such dysfunction might explain not only the somatosensory components of migraine, but also the auditory, olfactory, and visual components. Additionally, a locus coeruleus dysfunction may also explain the distractibility and anxiety often observed in migraine sufferers. ${ }^{36}$

An overview of the literature indicates that stress may be a predisposing factor for headache onset, acute headache trigger, and potential contributor to migraine progression. ${ }^{37}$

However, the relationship between migraine, stress, psychological symptoms, and response to treatment is complex and largely unknown. Géraud et al found that the majority of 5,417 migraine patients exhibited significant psychological symptoms, and most of patients were classified as anxious. ${ }^{38}$ Two-thirds of patients (67\%) suffered from anxiety (28\% from anxiety alone, 39\% from anxiety and depression), and 2\% from depression alone. Stress, avoidance, and catastrophizing, along with the number of headache days/month, the number of drugs taken during attacks, and migraine chronicity were the strongest predictive factors of migraine.

Several causal factors (low concentrations of glutamate, mitochondrial abnormalities, dysfunctions related to nitric oxide and calcium channelopathy, plasma protein extravasation, and dysfunctions of neuromodulatory structures in the brainstem) may converge onto a common hyperexcitable brain state, which constitutes the fundamental susceptibility to migraine attacks. ${ }^{39}$

\section{Migraine and prophylaxis}

Migraine is a cyclical pathology in which acute treatment is crucial for the patient's health during migraine-free intervals. It has been demonstrated that patients suffer not only in the acute episodes but also during the inter-critical period. ${ }^{13}$ Migraine sufferers are impaired in daily activities, ${ }^{32,33}$ and their health-related quality of life is generally poor compared both with the general population and with sufferers from other chronic disorders. ${ }^{40-42}$

Preventive therapy is essential in order to reduce recurrences and relapses and may be measured in terms of the reduction in the frequency of acute attacks, the impact of acute treatment on headache recurrence within the next 24 hours, as well as in a reduction in overall functional impairment.

Recent guidelines for the treatment of migraine suggest that patients who are candidates for prophylaxis should have the following features: more than two migraine attacks per month or migraine refractory to acute therapy, strong side effects of acute therapy, contraindication, failure of acute medication, use of acute medication more than twice per week, ${ }^{43,44}$ and a risk of overusing acute medication. ${ }^{22}$ Disability level, future pregnancy status, ${ }^{17}$ and the costs of acute and preventive therapy are aspects to be considered in initiating prophylaxis. ${ }^{22}$

The first goal of prophylactic treatment is to reduce the frequency and intensity of attacks, and, thereby, improve the quality of life..$^{6,17,20,45}$ The prophylactic therapy may cause problems in relation to adverse effects (fatigue, dizziness, reduced concentration, loss of appetite, weight gain, hair loss, changes in libido, and drowsiness), tolerability, cost, frequency of the dosage, the patient's compliance, and failure to complete treatment. ${ }^{18,21}$ Exploratory efficacy outcome measures should include: number of migraine attacks per four weeks, number of headache days, pain intensity, headache index, and global response. ${ }^{14,18,46}$ 
Several migraine preventive treatments have been recommended for improving negative disease outcome related to migraine. ${ }^{47}$

\section{Treatment options: medications}

There is a general agreement that propranolol, valproic acid, and topiramate are first-line treatments for migraine prophylaxis. ${ }^{48}$ Other drugs that are frequently used are flunarizine, amitriptyline, other betablockers, gabapentin, and methysergide. In addition, vitamins, natural medications, SSRIs such as paroxetine and fluvoxamine, tricyclic antidepressants (TCAs), and botulinum toxine have been tried. Evidence exists from several randomized controlled studies of the efficacy of anti-epileptic drugs, antidepressants, $\beta$-blockers, and calcium channel blockers in migraine prophylaxis. ${ }^{49}$ Combining pharmacological agents is useful if depression is present, but the side effects and patient dissatisfaction argue against the use of antidepressants for patients who suffer from migraine but without depression. ${ }^{6}$

An important issue here is the frequent abuse of medications such as nonsteroidal anti-inflammatory drugs and other analgesics, especially given their long-term side effects such as reduction of renal function. Headaches can be so frequent that patients use analgesics daily or nearly daily. Patients who abuse medications are particularly difficult to treat because prophylactic treatments are usually ineffective with these patients. ${ }^{50}$ Withdrawal from analgesics abuse is essential in order to improve both the patient's clinical condition and the analgesic abuse itself. ${ }^{51}$

\section{Antiepileptic drugs}

It is well demonstrated that anticonvulsants are effective in migraine treatment and prophylaxis. They reduce both the frequency of attacks (up to 1-2 attacks per month) as well as the number of attacks. Anticonvulsants are also well tolerated, and they cause fewer adverse effects..$^{22,39}$ Topiramate (TPM) and valproic acid (VPA) are the most important treatment options for migraine and are now approved for migraine prevention in several countries. ${ }^{52,53}$ Table 1 summarizes the most relevant studies on the efficacy of pharmacological agents in migraine prophylaxis.

VPA increases GABA levels in the brain and potentiates GABA-mediated responses. One possibly important action of VPA is the blockade of the degradation of GABA by GABA transaminase, thereby increasing GABA concentrations in both axons and glial cells. ${ }^{54}$ VPA has been found to block voltage-dependent sodium ion channels, thereby modulating the release of excitatory amino acids, and has also been found to block low threshold T-type calcium ion channels. ${ }^{55}$ The efficacy of VPA in migraine prevention has been shown in several double-blind, randomized, placebocontrolled studies. ${ }^{56,57}$

However, Apostol et al investigated the efficacy, tolerability, and safety of different doses of divalproex sodium extended-release vs placebo in the prophylaxis of migraine headaches in a 12-week, randomized, placebo-controlled, double-blind, parallel-group study in approximately 300 adolescents. ${ }^{58}$ They found that, although well tolerated, it did not differ from placebo in the prophylactic treatment of migraine headaches.

TPM is generally used to treat epilepsy, psychiatric disorders, and migraine prophylaxis and to suppress CSD frequency by $40 \%-80 \%$. Longer treatment durations produce stronger suppression. Direct and indirect effects on the inhibition of glutamate release and on blocking NMDA receptors may also be relevant for modulating migraine susceptibility. ${ }^{59}$

Large, multicentre, randomized, double-blind, placebocontrolled trials have demonstrated the efficacy of TPM in migraine prophylaxis in adults. ${ }^{60,61} \mathrm{~A}$ recent study showed a significant improvement in health-related quality of life in adult migraine patients. ${ }^{62-64}$ In four randomized placebo controlled trials, 6 months of TPM $(100 \mathrm{mg} / \mathrm{d})$ administration was associated with a significant decrease in monthly migraine frequency. ${ }^{50,60,61,65}$ However, a recent study suggests that a lower dose of TPM $(45.7 \mathrm{mg} / \mathrm{d})$ may also reduce migraine days and pain intensity. ${ }^{14}$ (For more details see Table 1). Feliu et al found significant reductions in acute migraine medication and medical resource use in 1,749 migraine sufferers in the six months following initiation of TPM preventive therapy. ${ }^{66}$ Vuković et al assessed the efficacy and safety of gabapentin at 900-1800 mg of drug in 3 doses in 67 migraine patients refractory to other prophylactic treatments, of which 52 completed the prospective, open-label study. ${ }^{67}$ They found a significant reduction in the number of days with headache, the use of acute medications and pain intensity in the prophylaxis of migraine.

Finally, in a cost-effectiveness analysis from three, double-blind, placebo-controlled, clinical trials of antiepileptic drugs studied for migraine prevention, Adelman, Adelman, and Von Seggern found that divalproex sodium was cost-effective in patients with 10 migraines per month, whereas gabapentin and topiramate became cost-effective for more than 10 migraines per month. ${ }^{68}$ 
Table I Most relevant literature studies reporting findings about the effectiveness of the majority of pharmacological agents in migraine prophylaxis

\begin{tabular}{lll}
\hline Study & Design & Sample size \\
\hline Gomersall and & $\begin{array}{l}\text { Double-blind } \\
\text { controlled clinical trial. }\end{array}$ & $\begin{array}{l}20 \text { subjects treated } \\
\text { Stuart }\end{array}$ \\
\end{tabular}

$\begin{array}{ll}\text { Hering and } & \text { Double blind study, valproate vs } \\ \text { Kuritzky }{ }^{57} & \text { placebo for } 8 \text { weeks. }\end{array}$

Linde et al ${ }^{115}$

Review including twenty-two randomized trials with a postrandomization observation period of at least 8 weeks comparing clinical effects of acupuncture intervention with a control group.

Schrader et $\mathrm{a}^{90} \quad$ Double blind, placebo controlled, crossover study.

Freitag et al ${ }^{56}$

Double blind randomized, placebo controlled, parallel-group study.

Linde and Rossnagel ${ }^{79}$

Lewis et al ${ }^{116}$

Review of I 66 controlled, randomized, and masked trials.

Dahlöf et a ${ }^{47}$ Longitudinal and responder analysis from 3 topiramate-placebo-controlled clinical trials.
29 patients divided into 2 groups; group I: valproate $400 \mathrm{mg}$ daily and group 2: placebo.

4419 participants.

Sixty patients aged 19-59 years with migraine with two to six episodes a month.

Treatment period of 12 weeks.

First treatment period

$10 \mathrm{mg}$ lisinopril/daily (one week)

$20 \mathrm{mg}$ lisinopril/daily (I I weeks)

Two week wash out period

Second treatment period

One placebo tablet/daily (one week).

Two placebo tablets/daily (I I weeks).

Subjects with 2 or more

migraine attacks in 4 weeks,

divided into 2 groups receiving

valproate $500-1000 \mathrm{mg}$

daily or placebo.

26 participants with placebo and 47 participants with other drugs.

Treatment options were separated into medications for acute headache and preventive medications. For preventive therapy, 12 agents were evaluated.

756 patients: 384 recived topiramate $100 \mathrm{mg} /$ daily and 372 received placebo.

\section{Conclusions}

Amitriptyline reduces both migraine attacks characterized by short warning and with no specific cause and those with long warning and recognized as due to fatigue. Amitriptyline was effective, irrespective of severity, only in reducing attacks with shorter duration.

More effectiveness of valproate than placebo in reducing severity and frequency of migraine attacks in $86.2 \%$ of patients.

Additional benefits with acupuncture in acute migraine attacks only or to routine care.

Lisoprinil vs placebo:

Hours with headache reduced by $20 \%$ Days with headache reduced by $17 \%$ Days with migraine reduced by $21 \%$ Headache severity reduced by $20 \%$ Days with migraine were reduced by at least $50 \%$ in 14 participants for active treatment vs placebo.

Days with migraine were fewer by at least $50 \%$ in 14 participants for active treatment vs placebo.

Mean reductions in 4-week migraine headache rate I.2 (from baseline 4.4) in the extended-release (ER) divalproex sodium group and 0.6 (from baseline 4.2) in the placebo group $(P=0.006)$. Significantly greater reductions in all three 4-week segments of the treatment period with $E R$ divalproex sodium than with placebo. Propranolol is more effective than placebo in the short-term interval treatment of migraine.

Evidence on long-term effects is lacking. Propranolol seems to be as effective and safe as a variety of other drugs used for migraine prophylaxis. Flunarizine is presumably effective and may be considered for prophylaxis but is not available in USA.

Significant improvement of topiramate $100 \mathrm{mg} /$ daily activities and patient functioning. Significant improvement of daily functioning and health status for those achieving $\geq 50 \%$ migraine frequency reduction. 
Table I (Continued)

\begin{tabular}{|c|c|c|c|}
\hline Study & Design & Sample size & Conclusions \\
\hline $\begin{array}{l}\text { Keskinbora and } \\
\text { Aydinli }^{6}\end{array}$ & $\begin{array}{l}\text { Single-center, } \\
\text { double-blind, } \\
\text { randomized and } \\
\text { controlled trial. }\end{array}$ & $\begin{array}{l}73 \text { patients with migraine with } \\
\text { or without aura. }\end{array}$ & $\begin{array}{l}\text { Amitriptyline and topiramate in } \\
\text { combination may be beneficial for } \\
\text { patients with migraine and comorbid } \\
\text { depression, particularly in terms of } \\
\text { side effects and associated displeasure } \\
\text { due to monotherapy. }\end{array}$ \\
\hline Dodick et al ${ }^{46}$ & $\begin{array}{l}\text { Multicenter, randomized, } \\
\text { double-blind, double-dummy, } \\
\text { parallel-group noninferiority study. }\end{array}$ & $\begin{array}{l}33 \text { I subjects } \\
\text { (I } 72 \text { topiramate, } \\
\text { I59 amitriptyline). }\end{array}$ & $\begin{array}{l}\text { Topiramate was at least as effective } \\
\text { as amitriptyline in reducing the rate of } \\
\text { mean monthly migraine episodes and } \\
\text { all pre-specified secondary efficacy } \\
\text { end points. } \\
\text { Topiramate was associated with } \\
\text { improvement in some quality of } \\
\text { life indicators compared with } \\
\text { amitriptyline, with weight loss and } \\
\text { improved weight satisfaction. }\end{array}$ \\
\hline Mullally et al ${ }^{105}$ & $\begin{array}{l}\text { Randomized, } \\
\text { prospective, single blind, } \\
\text { controlled trial for more than } \\
\text { one year. } \\
\text { Biofeedback + education } \\
\text { in pain theory + relaxation } \\
\text { technique vs education } \\
\text { in pain theory + relaxation } \\
\text { techniques alone. }\end{array}$ & $\begin{array}{l}\text { Sixty-four migraine } \\
\text { patients aged I8-55. }\end{array}$ & $\begin{array}{l}\text { Decrease in the frequency and } \\
\text { severity of the headaches in the first } \\
\text { I } 2 \text { months that continued to } \\
36 \text { months in education in pain theory } \\
\text { and relaxation techniques group. } \\
\text { Decreased number of medications } \\
\text { used and utilization of medical care. } \\
\text { No additional benefit in the } \\
\text { biofeedback group when compared to } \\
\text { simple relaxation techniques alone in } \\
\text { the treatment of migraine and tension } \\
\text { type headaches in adults. }\end{array}$ \\
\hline
\end{tabular}

\section{Triptans}

These agents are a major option for migraine management, but only about $50 \%-60 \%$ of patients consistently respond to this type of medication. ${ }^{69}$ In most cases, they provide only partial relief. Prophylactic treatment is indicated if other treatments are inadequate and if patients experience two or more migraine attacks per month. ${ }^{70}$

\section{Antidepressants}

Antidepressants have shown evidence for efficacy in the prophylactic treatment of migraine. ${ }^{27,71}$ Serotonin $(5-\mathrm{HT})$ and norepinephrine (NE) signalling play a role in some models of migraine pathophysiology. In general, among the antidepressants, amitriptyline (a tricyclic antidepressant) has well-demonstrated efficacy in migraine treatment. ${ }^{27,71}$

In evidence-based guidelines developed by Japanese Headache Society and the American Neurological Association, amitriptyline is classified as a Group 1 drug (an effective drug for the prevention of migraine attack). ${ }^{72}$ Moreover, amitriptyline is especially useful where there is comorbidity with depressive disorders. Administration of amitriptyline at low doses may reduce the frequency of side-effects such as sleepiness. Several clinical trials of this drug have also shown the remarkable benefits of amitriptyline in the prophylactic treatment of migraine attack. ${ }^{27,71}$ Table 1 summarizes the most relevant studies on the efficacy of amitriptyline in migraine prophylaxis.

Landy et al measured the baseline migraine frequency and severity over a 4-week period in twenty-seven subjects and found that sertraline, fluoxetine, fluvoxamine, and paroxetine are not as effective as conventional migraine prophylaxis medications such as beta-blockers, tricyclic antidepressants, or divalproex sodium whereas they may be effective in patients with comorbid depression who have failed conventional therapy. ${ }^{73}$

\section{$\beta$-blockers}

The improvement of migraine in patients who were given propranolol for angina pectoris revealed the effectiveness of propranolol in migraine prophylaxis. Available guidelines commonly recommend beta-blockers as the first choice for migraine prophylaxis. ${ }^{74}$ It is not certain how beta-blockers decrease the frequency of migraine attacks, ${ }^{74}$ but they may affect the central catecholaminergic system and serotonin receptors in the brain. The central action of $\beta$-blockers is probably mediated by inhibition of central $\beta$-receptors interfering with the vigilanceenhancing adrenergic pathways, interaction with 5-HT 
receptors and cross-modulation of the serotoninergic system. ${ }^{75}$ Propranolol inhibits CSD in rats by blocking glutamate release. ${ }^{76}$

Other beta-blocking drugs, such as nadolol, metoprolol, atenolol, timolol, and bisoprolol, have also been demonstrated to be effective in the prophylaxis of migraine. In contrast, several beta blockers with intrinsic sympathetic activity (ISA), such as alprenolol, oxprenolol, pindolol, and acebutolol, have not been demonstrated to be effective in migraine prophylaxis. ${ }^{77}$ Some case reports in the literature have reported successful treatment with amlodipine, a slow calcium-channel blocker in migraine prophylaxis. ${ }^{78}$ In a systematic review of 26 clinical trials, ${ }^{79}$ propranolol was shown to be more effective than placebo in reducing migraine frequency among adults. Seventeen trials out of 26 showed a significant superiority over placebo, while 7 showed a trend in favor of propranolol, and 2 showed no differences. In 13 clinical trials comparing propranolol with a calcium antagonist (flunazarizin in 7 cases), no difference was found in favor of propranolol in 12 clinical trials, while one found a trend in favor of flunarizin. In the same review, no difference was found in 7 of ten studies comparing propranolol with other beta-blockers, while in 3 trials a trend in favor of beta-blockers was seen. Comparisons of propranolol with other drugs such as femoxetine, tolfenamic acid, and 5-hydroxytryptophan, have shown that propranolol appears to be superior for the treatment of migraine patients. ${ }^{79}$ In a double-blind placebo-controlled cross-over study of migraine prophylaxis with propranolol $80 \mathrm{mg}$ once daily, $160 \mathrm{mg}$ once daily or placebo for two months in thirty migraine sufferers, al-Qassab and Findley found no significant differences between the three treatments in headache frequency, headache severity, nausea frequency, or severity. ${ }^{80}$

Pascaul et al explored treatment combining a beta-blocker plus topiramate in migraine patients previously resistant to either medication in monotherapy, and found that the combination of beta-blocker plus topiramate demonstrated a benefit in $60 \%$ of patients who had not previously responded to monotherapy. ${ }^{81}$

\section{Flunarizine}

The primary pharmacological mechanism of flunarizine on burst potentials has been attributed to the blockage of calcium or sodium ion channels. Flunarizine has been used frequently $(32 \%)$ for prophylactic treatment, and it has been considered to be a first-choice medication for the management of patients with migraine. ${ }^{82}$ It has also been reported that flunarizine might be a useful add-on treatment in therapy-resistant forms of epilepsy. ${ }^{83,84}$

Both flunarizine and propranolol have demonstrable efficacy in the prophylaxis of migraine, ${ }^{79,85}$ but no significant difference in efficacy was observed between sodium valproate at $1000 \mathrm{mg}$ versus flunarizine at $10 \mathrm{mg}$ daily maintained for 4 weeks. ${ }^{86}$ Diener et al reported that $10 \mathrm{mg}$ flunarizine daily is at least as effective as $160 \mathrm{mg}$ propranolol in the prophylaxis of migraine after 16 weeks of treatment, and $5 \mathrm{mg}$ flunarizine proved to be at least as effective as $160 \mathrm{mg}$ propranolol when looking at the mean attack frequency for both the whole double-blind period and the last 28 days of treatment. ${ }^{87}$

Lucetti et al found that family history, a high intensity of pain, frequent attacks and a history of analgesic abuse were the most important predictive factors for a positive response to flunarizine in migraine prophylaxis. ${ }^{88}$

Wöber et al reported that therapeutic success with flunarizine and beta blockers dramatically decreases in the majority of patients several months after discontinuation of treatment, and further long-term prophylaxis is more effective if the substance class is changed. ${ }^{89}$

\section{Pizotifen and naproxen}

There is consistent evidence to support pizotifen's efficacy in migraine prevention. ${ }^{90,91}$ In a comparative study, pizotifen was more effective than naproxen sodium and placebo in migraine prophylaxis. However, in a recent review of 16 published randomized controlled trials of naproxen in the treatment of migraine, naproxen sodium was more effective than placebo in reducing pain intensity and providing a pain-free state within 2 hours in adults with moderate or severe migraine attacks. ${ }^{92}$

The mechanism of action of pizotifen is not known for certain, but pizotifen has additional antagonistic effects on 5-HT2, histamine H1, muscarinic cholinergic, $\alpha-1$ adrenergic, $\alpha$-2-adrenergic, and dopamine receptors. ${ }^{90,91,93}$

\section{Angiotensin II receptor blockers}

The angiotensin-converting enzyme (ACE) inhibitor lisinopril has been found to be an effective prophylactic treatment for migraine attacks. ${ }^{94}$ In addition, candesartan is a long-acting angiotensin II type 1 (AT1) receptor blocker with a high affinity for the AT1 receptor that has demonstrated efficacy in migraine prophylaxis. ${ }^{95}$ However, the mechanism of action of ACE inhibitors in migraine prevention is poorly understood.

\section{Other drugs}

Other options for migraine prophylaxis exist, but the evidence in support of their use is not robust or well-documented. 
All of these drugs have varying degrees of adverse effects, and some of these effects may limit their use. ${ }^{95}$ There are additional agents such as vitamins, natural medications, and botulinum toxine, which have shown to have possibilities in migraine prophylaxis.

\section{Botulinum toxin type A (BoNTA)}

Patients whose migraines are poorly controlled by traditional preventive therapies may be treated with Botulinum Toxin type A (BoNTA). ${ }^{5,18,21}$ BoNTA is more effective in patients with chronic migraine. It may be used in migraine patients with the following features: muscular stress as a migraine trigger, craniocervical dystonia, pericranial painful muscular trigger points, and oromandibular dysfunction. BoNTA is highly recommended for patients with poor compliance because of its method of action, its long duration of action and for the lack of the usual side-effects caused by prophylaxis. ${ }^{5,18,21}$ BoNTA has beneficial effects on the frequency of migraine but not in lowering the severity of pain. . $18,21^{2}$

Jakubowski et al found that exploding headaches (a build-up of pressure inside the head) were impervious to extracranial BoNTA injections consistent with the prevailing view that migraine pain is mediated by intracranial innervation. ${ }^{96}$ The response of imploding headaches (feeling crushed by external forces) and ocular headaches to BoNTA treatment suggests that these types of migraine pain involve extracranial innervation.

\section{Feverfew}

Feverfew (Tanacetum Parthenium) is derived from dried chrysanthemum leaves. Some studies have demonstrated that Feverfew showed greater benefits than placebo in two-third of patients, and that adverse effect were greater with placebo $(10.2 \%)$ than with feverfew $(8.4 \%))^{19,97,98}$

In a randomized, double-blind, multicentre, controlled trial, Pfaffenrath et al compared the clinical efficacy and safety of three dosages of feverfew $(2.08,6.25$, and $18.75 \mathrm{mg})$ with placebo. ${ }^{99}$ They found that feverfew showed a significant migraine prophylactic effect, but only in a small subgroup of patients with at least four attacks during the 28-day baseline period. The most favorable benefit-risk ratio was observed with a dosage of $18.75 \mathrm{mg}$ of feverfew daily.

\section{Petasites hybridus, magnesium, riboflavin, coenzyme Q10}

Petasites hybridus is a European wild herb, and extracts of the roots are used for the treatment of pain. It seems to be effective in reducing migraine attack frequency if administered in doses $>50 \mathrm{mg}$ bid. ${ }^{19}$ Petasites hybridus's adverse effects are similar to those of a placebo.

Magnesium has been shown to be effective in acute treatment, while no significant improvement has been shown in preventive treatment. ${ }^{19}$ However, in a randomized doubleblind placebo-controlled trial in 120 patients of a compound providing a daily dose of riboflavin $400 \mathrm{mg}$, magnesium $300 \mathrm{mg}$, and feverfew $100 \mathrm{mg}$, Maizels, Blumenfeld, and Burchette found that riboflavin $25 \mathrm{mg}$ showed an effect comparable to a combination of riboflavin $400 \mathrm{mg}$, magnesium $300 \mathrm{mg}$, and feverfew $100 \mathrm{mg} .{ }^{100}$

Schoenen, Jacquy, and Lenaerts found that riboflavin is an interesting option for migraine prophylaxis because of its high efficacy, excellent tolerability, and low cost. ${ }^{101}$

However, there is also conflicting scientific evidence with regard to the efficacy of these compounds for migraine prophylaxis, but the combination of these various natural drugs might bring some improvement in migraine frequency and number of headache days. ${ }^{19}$

\section{Nonmedication treatment}

Therapy that does not involve medications may provide symptomatic relief. Biofeedback and relaxation techniques may be helpful for stopping an attack once it has started, and better sleep is another possible outcome. Preventing migraine requires motivation on the part of the patient to make some life changes. Patients can be educated as to triggering factors that can be avoided, including smoking cessation ${ }^{102}$ and avoiding certain foods, especially those high in tyramine or those containing sulphites or nitrates. ${ }^{103}$ Generally, leading a healthy life style, with good nutrition, adequate water intake, sufficient sleep and exercise, may be useful. Acupuncture has also been suggested as useful. ${ }^{20}$

\section{Biofeedback and relaxation therapy}

Behavioral interventions, particularly biofeedback and relaxation therapy, have demonstrated their effectiveness in controlled trials for the treatment of both adults and older children with migraine, often permitting patients to decrease their dependence on medication. The physiological basis for their effectiveness is unclear, but data from one trial suggest that levels of plasma beta-endorphin can be altered by relaxation and biofeedback therapies. Biofeedback is an established nonpharmacologic technique commonly used in the treatment of migraine and tension-type headaches. Research has also suggested that biofeedback may result in a decrease in medical utilization. ${ }^{104,105}$ 
Biofeedback and relaxation therapy can also be important tools in migraine prophylaxis in terms of the frequency of attacks and drug reduction, but biofeedback is more costly and does not have any additional benefit when compared to simple relaxation techniques alone.

\section{Sleep and melatonin}

The quality and quantity of sleep is decreased in patients with migraine. ${ }^{106,107}$ The pineal gland involved in the sleepwake cycle may be involved in migraine physiopathology. Specifically, pineal gland irregularity may be the physical origin of migraine headaches, with subsequent physiological changes being secondary. Research has found that the level of the pineal hormone melatonin is low in migraine patients. ${ }^{108}$ According to this theory, the administration of melatonin may normalize this circadian cycle, and it may play a role in re-synchronizing biological rhythms to lifestyle and in relieving migraines and other forms of headaches. ${ }^{108}$ Research testing the administration of melatonin found that it was safe for migraine sufferers, with few or no sideeffects. Additionally, several studies have found administering melatonin to migraine sufferers relieved pain and decreased headache recurrence in some cases. It has been suggested, therefore, that melatonin may play an important therapeutic role in the treatment of migraines and other types of headaches. ${ }^{109}$

\section{Acupuncture}

Acupuncture is often used for migraine prophylaxis as it reduces the frequency and intensity of attacks and does not have side-effects..$^{20}$ It has been demonstrated that the addition of acupuncture to active treatment is beneficial for the three months after the migraine attack. ${ }^{20}$ Acupuncture may, therefore, be an effective adjunct to basic care and prophylactic treatment when used together with drugs that are superior to placebo. ${ }^{20}$

\section{New treatments}

New therapies have been proposed for the treatment of drug-resistant primary headache. For example, peripheral neurostimulation has been proposed for the treatment of a number of types of chronic daily headache that do not respond to prophylaxis. ${ }^{15,16,109-112}$ Experimental studies indicate that it may have an antidolorific effect, ${ }^{92,113}$ and may affect brain areas involved in pain modulation. ${ }^{111}$ However, a recent study suggests that the use of the neurostimulation technique may increase analgesic overuse (including opioids). The role of psychiatric disorders or other comorbidities and uncertainty as to which types of headaches respond to this type of treatment argue against its use at the present time. ${ }^{67}$

\section{Limitations of this review}

The major problem encountered in undertaking this review was the highly variable and often insufficient reporting of the complex outcome data. Additionally, migraine prophylaxis trials typically use headache diaries to monitor the course of the disease. From these headache diaries, a variety of outcomes can be extracted including: headache days, migraine days, migraine attacks, days with a defined headache intensity, attack intensity, mean headache intensity, headache indices, headache hours, days with medication and use of analgesics. The outcomes were assessed over different time frames ranging from 3 to 8 weeks. Patient outcomes were also presented in different ways such as means with standard deviations, standard errors, confidence intervals; medians with range or quartiles; and as mean or median percent change compared to baseline.

\section{Discussion}

Migraine is a cyclical illness that needs correct treatment of acute attacks, but also an adequate treatment prophylaxis to reduce the intercritical pain. The benefits of preventive pharmacotherapy for migraine should be measured over time in terms of changes in the frequency of acute attacks, the impact of acute treatment on headache recurrence within the next 24 hours, and the reduction of overall functional and psychosocial impairment. Although most data reported in the studies reviewed were heterogeneous, we may conclude that the most effective pharmacological treatment for migraine prophylaxis includes propranolol, some anticonvulsants such as topiramate, valproic acid, and amitriptyline. There was a suggestion of some benefit from alternative therapies such as riboflavin and coenzyme Q10, but they appear to have little effect, and only a combination of various natural drugs might bring some improvement in terms of migraine frequency and number of headache days. Other nonmedications approaches may play a role in migraine prophylaxis, and they have been proposed for the treatment of chronic daily headache that does not respond to prophylaxis.

Another consideration that should be taken into account is related to the complex relationship between migraine, stress, psychological symptoms, and response to treatment. The majority of migraine patients exhibit significant psychological symptoms, particularly stress, anxiety, and a combination of both anxiety and depression. Stress is 
considered to be one of the most relevant predictive factors for migraine reoccurrence. Anxiety, depression, and stress often have negative consequences on patient outcome. Most migraine sufferers do not treat themselves in anticipation of the headache, and they often returned unused quantities of drugs to physicians. The correct assessment of anxiety, depression, and stress appear critical for developing an adequate preventive treatment strategy.

\section{Conclusion}

Optimizing the treatment outcome and reducing the frequency of episodes may help to alleviate the cycle of migraines. Several studies were identified that clearly supported the importance of pharmacotherapy in migraine prophylaxis. Combining comprehensive care and preventive therapy in adult migraine sufferers is presumably the most appropriate strategy for improving long-term outcome in migraine. An adequate prophylaxis is crucial for reducing disability and preventing the evolution of migraine into a chronic progressive illness.

\section{Disclosure}

No conflicts of interest were declared in relation to this paper.

\section{References}

1. Pompili M, Di Cosimo D, Innamorati M, Lester D, Tatarelli R, Martelletti P. Psychiatric comorbidity in patients with chronic daily headache and migraine: a selective overview including personality traits and suicide risk. J Headache Pain. 2009;10(4):283-290.

2. Castillo J, Munoz P, Guitera V, Pascual J. Kaplan Award 1998. Epidemiology of chronic daily headache in the general population. Headache. 1999;39(3):190-196.

3. Headache Classification Committee of the International Headache Society. The International Classification of Headache Disorders: 2nd edition. Cephalalgia. 2004;24(Suppl 1):9-160.

4. Breslau N, Davis GC. Migraine, physical health and psychiatric disorder: a prospective epidemiologic study in young adults. JPsychiatr Res. 1993;27(2):211-221.

5. Aurora SK, Gawel M, Brandes JL, Pokta S, Vandenburgh AM. Botulinum toxin type a prophylactic treatment of episodic migraine: a randomized, double-blind, placebo-controlled exploratory study. Headache. 2007;47(4):486-499.

6. Keskinbora K, Aydinli I. A double-blind randomized controlled trial of topiramate and amitriptyline either alone or in combination for the prevention of migraine. Clin Neurol Neurosurg. 2008; 110(10):979-984.

7. Verri AP, Proietti Cecchini A, Galli C, Granella F, Sandrini G, Nappi G. Psychiatric comorbidity in chronic daily headache. Cephalalgia. 1998;18 (Suppl 21):45-49.

8. Mathew N. Chronic daily headache: clinical features and natural history. In: Nappi G, ed. Headache and Depression: Serotonin Pathways as a Common Clue. New York, NY: Raven Press; 1991:49-58.

9. Peres MF, Zukerman E, Young WB, Silberstein SD. Fatigue in chronic migraine patients. Cephalalgia. 2002;22(9):720-724.

10. Peres MF, Young WB, Kaup AO, Zukerman E, Silberstein SD. Fibromyalgia is common in patients with transformed migraine. Neurology. 2001;57(7):1326-1328.
11. Silberstein SD. Treatment recommendations for migraine. Nat Clin Pract Neurol. 2008;4(9):482-489.

12. Scher AI, Stewart WF, Lipton RB. The comorbidity of headache with other pain syndromes. Headache. 2006;46(9):1416-1423.

13. Freitag FG. The cycle of migraine: patients' quality of life during and between migraine attacks. Clin Ther. 2007;29(5):939-949.

14. Nelles G, Delbruck A, Schulze L, et al. Topiramate for migraine prevention in a naturalistic setting: results from an open label, flexible dose study. Headache. 2009;49(10):1454-1465.

15. Andlin-Sobocki P, Jonsson B, Wittchen HU, Olesen J. Cost of disorders of the brain in Europe. Eur J Neurol. 2005;12(Suppl 1):1-27.

16. Stewart WF, Ricci JA, Chee E, Hahn SR, Morganstein D. Cost of lost productive work time among US workers with depression. JAMA. 2003;289(23):3135-3144.

17. Moschiano F, D'Amico D, Bussone G. Migraine prophylaxis: key points for the practising clinician. Neurol Sci. 2009;30(Suppl 1): S33-S37.

18. Cady R, Schreiber C. Botulinum toxin type A as migraine preventive treatment in patients previously failing oral prophylactic treatment due to compliance issues. Headache. 2008;48(6):900-913.

19. Evans RW, Taylor FR. "Natural" or alternative medications for migraine prevention. Headache. 2006;46(6):1012-1018.

20. Linde K, Allais G, Brinkhaus B, Manheimer E, Vickers A, White AR. Acupuncture for migraine prophylaxis. Cochrane Database Syst Rev. 2009(1):CD001218.

21. Gobel H. Botulinum toxin in migraine prophylaxis. J Neurol. 2004;251 (Suppl 1):I8-11.

22. Chronicle E, Mulleners W. Anticonvulsant drugs for migraine prophylaxis. Cochrane Database Syst Rev. 2004;(3):CD003226.

23. Stewart WF, Lipton RB, Celentano DD, Reed ML. Prevalence of migraine headache in the United States. Relation to age, income, race, and other sociodemographic factors. JAMA. 1992;267(1):64-69.

24. Lipton RB, Stewart WF, Diamond S, Diamond ML, Reed M. Prevalence and burden of migraine in the United States: data from the American Migraine Study II. Headache. 2001;41(7):646-657.

25. Benamer HT, Deleu D, Grosset D. Epidemiology of headache in Arab countries. J Headache Pain. 2010;11(1):1-3.

26. Rasmussen BK. Epidemiology of migraine. Biomed Pharmacother. $1995 ; 49(10): 452-455$.

27. Ramadan NM, Buchanan TM. New and future migraine therapy. Pharmacol Ther. 2006;112(1):199-212.

28. Bolay H, Reuter U, Dunn AK, Huang Z, Boas DA, Moskowitz MA. Intrinsic brain activity triggers trigeminal meningeal afferents in a migraine model. Nat Med. 2002;8(2):136-142.

29. Haut SR, Bigal ME, Lipton RB. Chronic disorders with episodic manifestations: focus on epilepsy and migraine. Lancet Neurol. 2006;5(2):148-157.

30. Piao ZG, Cho IH, Park CK, et al. Activation of glia and microglial p38 MAPK in medullary dorsal horn contributes to tactile hypersensitivity following trigeminal sensory nerve injury. Pain. 2006;121(3): 219-231.

31. Burstein R, Cutrer MF, Yarnitsky D. The development of cutaneous allodynia during a migraine attack clinical evidence for the sequential recruitment of spinal and supraspinal nociceptive neurons in migraine. Brain. 2000;123(Pt 8):1703-1709.

32. Moskowitz MA. Basic mechanisms in vascular headache. Neurol Clin. 1990;8(4):801-815.

33. Buzzi MG, Moskowitz MA. The antimigraine drug, sumatriptan (GR43175), selectively blocks neurogenic plasma extravasation from blood vessels in dura mater. Br J Pharmacol. 1990;99(1):202-206.

34. May A, Goadsby PJ. Pharmacological opportunities and pitfalls in the therapy of migraine. Curr Opin Neurol. 2001;14(3):341-345.

35. Peroutka SJ. Neurogenic inflammation and migraine: implications for the therapeutics. Mol Interv. 2005;5(5):304-311.

36. Aston-Jones G, Cohen JD. An integrative theory of locus coeruleusnorepinephrine function: adaptive gain and optimal performance. Annu Rev Neurosci. 2005;28:403-450. 
37. Nash JM, Thebarge RW. Understanding psychological stress, its biological processes, and impact on primary headache. Headache. 2006;46(9):1377-1386.

38. Geraud G, Valade D, Lanteri-Minet M, et al. SMILE: first observational prospective cohort study of migraine in primary care in France. Description of methods and study population. Cephalalgia. 2008; 28(2):164-173.

39. Welch KM, D'Andrea G, Tepley N, Barkley G, Ramadan NM. The concept of migraine as a state of central neuronal hyperexcitability. Neurol Clin. 1990;8(4):817-828.

40. D’Amico D, Usai S, Grazzi L, Solari A, Curone M, Bussone G. The impact of primary headaches on patients'lives: Italian experience with the MIDAS and the SF-36 questionnaires. Headache Care. 2004; $1: 123-128$.

41. Osterhaus JT, Townsend RJ, Gandek B, Ware JE, Jr. Measuring the functional status and well-being of patients with migraine headache. Headache. 1994;34(6):337-343.

42. Terwindt GM, Ferrari MD, Tijhuis M, Groenen SM, Picavet HS, Launer LJ. The impact of migraine on quality of life in the general population: the GEM study. Neurology. 2000;55(5):624-629.

43. Silberstein SD. Practice parameter: evidence-based guidelines for migraine headache (an evidence-based review): report of the Quality Standards Subcommittee of the American Academy of Neurology. Neurology. 2000;55(6):754-762.

44. Diener HC, Brune K, Gerber WD, Pfaffenrath V, Straube A. Therapy of the acute migraine attack and migraine prophylaxis. Recommendation of the "Deutsche Migrane- und Kopfschmerz-Gesellschaft. Schmerz. 2000;14(4):269-283

45. Mulleners WM, Chronicle EP. Anticonvulsants in migraine prophylaxis a Cochrane review. Cephalalgia. 2008;28(6):585-597.

46. Dodick DW, Freitag F, Banks J, et al. Topiramate versus amitriptyline in migraine prevention: a 26-week, multicenter, randomized, double-blind, double-dummy, parallel-group noninferiority trial in adult migraineurs. Clin Ther. 2009;31(3):542-559.

47. Dahlof C, Loder E, Diamond M, Rupnow M, Papadopoulos G, Mao L. The impact of migraine prevention on daily activities: a longitudinal and responder analysis from three topiramate placebo-controlled clinical trials. Health Qual Life Outcomes. 2007;5:56.

48. Modi S, Lowder DM. Medications for migraine prophylaxis. Am Fam Physician. 2006;73(1):72-78.

49. Galletti F, Cupini LM, Corbelli I, Calabresi P, Sarchielli P. Pathophysiological basis of migraine prophylaxis. Prog Neurobiol. 2009;89(2): 176-192.

50. Diener HC, Limmroth V. Medication-overuse headache: a worldwide problem. Lancet Neurol. 2004;3(8):475-483.

51. Grazzi L, Andrasik F, Usai S, Bussone G. Treatment of chronic migraine with medication overuse: is drug withdrawal crucial? Neurol Sci. 2009;30(Suppl 1):S85-88.

52. Shank RP, Gardocki JF, Streeter AJ, Maryanoff BE. An overview of the preclinical aspects of topiramate: pharmacology, pharmacokinetics, and mechanism of action. Epilepsia. 2000;41(Suppl 1):S3-S9.

53. Schurks M, Diener HC, Goadsby P. Update on the prophylaxis of migraine. Curr Treat Options Neurol. 2008;10(1):20-29.

54. Terbach N, Williams RS. Structure-function studies for the panacea, valproic acid. Biochem Soc Trans. 2009;37(Pt 5):1126-1132.

55. Loscher W. Valproate: a reappraisal of its pharmacodynamic properties and mechanisms of action. Prog Neurobiol. 1999;58(1):31-59.

56. Freitag FG, Collins SD, Carlson HA, et al. A randomized trial of divalproex sodium extended-release tablets in migraine prophylaxis. Neurology. 2002;58(11):1652-1659.

57. Hering R, Kuritzky A. Sodium valproate in the prophylactic treatment of migraine: a double-blind study versus placebo. Cephalalgia. 1992; 12(2):81-84

58. Apostol G, Cady RK, Laforet GA, et al. Divalproex extended-release in adolescent migraine prophylaxis: results of a randomized, double-blind, placebo-controlled study. Headache. 2008;48(7): 1012-1025.
59. Ayata C, Jin H, Kudo C, Dalkara T, Moskowitz MA. Suppression of cortical spreading depression in migraine prophylaxis. Ann Neurol. 2006;59(4):652-661.

60. Bussone G, Diener HC, Pfeil J, Schwalen S. Topiramate $100 \mathrm{mg}$ /day in migraine prevention: a pooled analysis of double-blind randomised controlled trials. Int J Clin Pract. 2005;59(8):961-968.

61. Brandes JL, Saper JR, Diamond M, et al. Topiramate for migraine prevention: a randomized controlled trial. JAMA. 2004;291(8): 965-973.

62. Lakshmi CV, Singhi P, Malhi P, Ray M. Topiramate in the prophylaxis of pediatric migraine: a double-blind placebo-controlled trial. J Child Neurol. 2007;22(7):829-835.

63. Winner P, Gendolla A, Stayer C, et al. Topiramate for migraine prevention in adolescents: a pooled analysis of efficacy and safety. Headache. 2006;46(10):1503-1510.

64. Diamond M, Dahlof C, Papadopoulos G, Neto W, Wu SC. Topiramate improves health-related quality of life when used to prevent migraine. Headache. 2005;45(8):1023-1030.

65. Silberstein SD, Neto W, Schmitt J, Jacobs D. Topiramate in migraine prevention: results of a large controlled trial. Arch Neurol. 2004;61(4):490-495.

66. Feliu AL, Rupnow MF, Blount A, Boccuzzi SJ, Vermilyea J. Resource use associated with topiramate in migraine prophylaxis. Am J Health Syst Pharm. 2007;64(14):1483-1491.

67. Vukovic V, Lovrencic-Huzjan A, Bosnar-Puretic M, Demarin V. The efficacy of gabapentin in migraine prophylaxis: an observational open label study. Acta Clin Croat. 2009;48(2):145-151.

68. Adelman JU, Adelman LC, von Seggern R. Cost-effectiveness of antiepileptic drugs in migraine prophylaxis. Headache. 2002; 42(10): 978-983.

69. Ferrari MD, Roon KI, Lipton RB, Goadsby PJ. Oral triptans (serotonin 5-HT(1B/1D) agonists) in acute migraine treatment: a meta-analysis of 53 trials. Lancet. 2001;358(9294):1668-1675.

70. Massiou H. Prophylactic treatments of migraine. Rev Neurol (Paris). 2000;156(Suppl 4):4S79-S86.

71. Buchanan TM, Ramadan NM. Prophylactic pharmacotherapy for migraine headaches. Semin Neurol. 2006;26(2):188-198.

72. Nagata E. Antidepressants in migraine prophylaxis. Brain Nerve. 2009; 61(10):1131-1134.

73. Landy S, McGinnis J, Curlin D, Laizure SC. Selective serotonin reuptake inhibitors for migraine prophylaxis. Headache. 1999;39(1): 28-32.

74. Silberstein SD, Goadsby PJ. Migraine: preventive treatment Cephalalgia. 2002;22(7):491-512.

75. Koella WP. CNS-related (side-)effects of beta-blockers with special reference to mechanisms of action. Eur J Clin Pharmacol. 1985;28 (Suppl:)55-63.

76. Richter F, Mikulik O, Ebersberger A, Schaible HG. Noradrenergic agonists and antagonists influence migration of cortical spreading depression in rat-a possible mechanism of migraine prophylaxis and prevention of postischemic neuronal damage. J Cereb Blood Flow Metab. 2005;25(9):1225-1235.

77. Shimizu T. Beta blockers in migraine prophylaxis. Brain Nerve. 2009; 61(10):1125-1130.

78. Dandapani BK, Hanson MR. Amlodipine for migraine prophylaxis Headache. 1998;38(8):624-626.

79. Linde K, Rossnagel K. Propranolol for migraine prophylaxis. Cochrane Database Syst Rev. 2004(2):CD003225.

80. al-Qassab HK, Findley LJ. Comparison of propranolol LA $80 \mathrm{mg}$ and propranolol LA $160 \mathrm{mg}$ in migraine prophylaxis: a placebo controlled study. Cephalalgia. 1993;13(2):128-131.

81. Pascual J, Rivas MT, Leira R. Testing the combination beta-blocker plus topiramate in refractory migraine. Acta Neurol Scand. 2007; 115(2):81-83.

82. Martinez HR, Londono O, Cantu-Martinez L, del Carmen Tarin L, Castillo CD. Topiramate as an adjunctive treatment in migraine prophylaxis. Headache. 2003;43(10):1080-1084. 
83. Lawrence ER, Hossain M, Littlestone W. Sanomigran for migraine prophylaxis, controlled multicenter trial in general practice. Headache. 1977;17(3):109-112.

84. Bellavance AJ, Meloche JP. A comparative study of naproxen sodium, pizotyline and placebo in migraine prophylaxis. Headache. 1990;30(11):710-715.

85. Reveiz-Herault L, Cardona AF, Ospina EG, Carrillo P. Effectiveness of flunarizine in the prophylaxis of migraine: a meta-analytical review of the literature. Rev Neurol. 2003;36(10):907-912.

86. Mitsikostas DD, Polychronidis I. Valproate versus flunarizine in migraine prophylaxis: a randomized, double-open, clinical trial. Funct Neurol. 1997;12(5):267-276.

87. Diener HC, Matias-Guiu J, Hartung E, et al. Efficacy and tolerability in migraine prophylaxis of flunarizine in reduced doses: a comparison with propranolol $160 \mathrm{mg}$ daily. Cephalalgia. 2002;22(3):209-221.

88. Lucetti C, Nuti A, Pavese N, Gambaccini G, Rossi G, Bonuccelli U. Flunarizine in migraine prophylaxis: predictive factors for a positive response. Cephalalgia. 1998;18(6):349-352.

89. Wober C, Wober-Bingol C, Koch G, Wessely P. Long-term results of migraine prophylaxis with flunarizine and beta-blockers. Cephalalgia. 1991;11(6):251-256.

90. Schrader H, Stovner LJ, Helde G, Sand T, Bovim G. Prophylactic treatment of migraine with angiotensin converting enzyme inhibitor (lisinopril): randomised, placebo controlled, crossover study. BMJ. 2001;322(7277):19-22.

91. Mylecharane EJ. 5-HT2 receptor antagonists and migraine therapy. J Neurol. 1991;238(Suppl 1):S45-52.

92. Suthisisang CC, Poolsup N, Suksomboon N, Lertpipopmetha V, Tepwitukgid B. Meta-analysis of the efficacy and safety of naproxen sodium in the acute treatment of migraine. Headache. 2010;50(5):808-818.

93. Tronvik E, Stovner LJ, Helde G, Sand T, Bovim G. Prophylactic treatment of migraine with an angiotensin II receptor blocker: a randomized controlled trial. JAMA. 2003;289(1):65-69.

94. Henneicke-von Zepelin HH. Feverfew for migraine prophylaxis. Headache. 2006;46(3):531.

95. Tietjen GE, Brandes JL, Peterlin BL, et al. Allodynia in migraine: association with comorbid pain conditions. Headache. 2009;49(9): 1333-1344.

96. Jakubowski M, McAllister PJ, Bajwa ZH, Ward TN, Smith P, Burstein R. Exploding vs imploding headache in migraine prophylaxis with Botulinum Toxin A. Pain. 2006;125(3):286-295.

97. Eidlitz-Markus T, Haimi-Cohen Y, Steier D, Zeharia A. Effectiveness of nonpharmacologic treatment for migraine in young children. Headache. 50(2):219-223.

98. Shrivastava R, Pechadre JC, John GW. Tanacetum parthenium and Salix alba (Mig-RL) combination in migraine prophylaxis: a prospective, open-label study. Clin Drug Investig. 2006;26(5):287-296.

99. Pfaffenrath V, Diener HC, Fischer M, Friede M, Henneicke-von Zepelin HH. The efficacy and safety of Tanacetum parthenium (feverfew) in migraine prophylaxis - a double-blind, multicentre, randomized placebo-controlled dose-response study. Cephalalgia. 2002;22(7): $523-532$.
100. Maizels M, Blumenfeld A, Burchette R. A combination of riboflavin, magnesium, and feverfew for migraine prophylaxis: a randomized trial. Headache. 2004;44(9):885-890.

101. Schoenen J, Jacquy J, Lenaerts M. Effectiveness of high-dose riboflavin in migraine prophylaxis. A randomized controlled trial. Neurology. 1998;50(2):466-470.

102. Hu J, Wu ZC, Wang JJ, Jiao Y. Comparison between modern and ancient thoughts about acupuncture treatment of migraine. Zhen $\mathrm{Ci}$ Yan Jiu. 2009;34(4):276-278.

103. Millea PJ, Brodie JJ. Tension-type headache. Am Fam Physician. 2002;66(5):797-804.

104. Seidel S, Hartl T, Weber M, et al. Quality of sleep, fatigue and daytime sleepiness in migraine - a controlled study. Cephalalgia. 2009;29(6):662-669.

105. Mullally WJ, Hall K, Goldstein R. Efficacy of biofeedback in the treatment of migraine and tension type headaches. Pain Physician. 2009;12(6):1005-1011.

106. Magis D, Allena M, Bolla M, De Pasqua V, Remacle JM, Schoenen J. Occipital nerve stimulation for drug-resistant chronic cluster headache: a prospective pilot study. Lancet Neurol. 2007;6(4):314-321.

107. Gagnier JJ. The therapeutic potential of melatonin in migraines and other headache types. Altern Med Rev. 2001;6(4):383-389.

108. Burns B, Watkins L, Goadsby PJ. Treatment of medically intractable cluster headache by occipital nerve stimulation: long-term follow-up of eight patients. Lancet. 2007;369(9567):1099-1106.

109. Matharu MS, Bartsch T, Ward N, Frackowiak RS, Weiner R, Goadsby PJ. Central neuromodulation in chronic migraine patients with suboccipital stimulators: a PET study. Brain. 2004;127(Pt 1): 220-230

110. Multon S, Schoenen J. Pain control by vagus nerve stimulation: from animal to man...and back. Acta Neurol Belg. 2005;105(2):62-67.

111. Goadsby PJ, Bartsch T, Dodick DW. Occipital nerve stimulation for headache: mechanisms and efficacy. Headache. 2008;48(2): 313-318.

112. Schwedt TJ, Dodick DW, Hentz J, Trentman TL, Zimmerman RS. Occipital nerve stimulation for chronic headache - long-term safety and efficacy. Cephalalgia. 2007;27(2):153-157.

113. Leone M, Proietti Cecchini A, Mea E, et al. Therapeutic neurostimulation in chronic headaches: problems of patient selection. Neurol Sci. 2008;29(Suppl 1):S59-61.

114. Gomersall JD, Stuart A. Amitriptyline in migraine prophylaxis. Changes in pattern of attacks during a controlled clinical trial. J Neurol Neurosurg Psychiatry. 1973;36(4):684-690.

115. Linde K, Vickers A, Hondras M, et al. Systematic reviews of complementary therapies - an annotated bibliography. Part 1: acupuncture. BMC Complement Altern Med. 2001;1:3.

116. Lewis D, Ashwal S, Hershey A, Hirtz D, Yonker M, Silberstein S. Practice parameter: pharmacological treatment of migraine headache in children and adolescents: report of the American Academy of Neurology Quality Standards Subcommittee and the Practice Committee of the Child Neurology Society. Neurology. 2004; 63(12):2215-2224.
Patient Related Outcome Measures

\section{Publish your work in this journal}

Patient Related Outcome Measures is an international, peer-reviewed, open access journal focusing on treatment outcomes specifically relevant to patients. All aspects of patient care are addressed within the journal and practitioners from all disciplines are invited to submit their work as well as healthcare researchers and patient support groups. Areas covered will Submit your manuscript here: http://www.dovepress.com/patient-related-outcome-measures-journal

\section{Dovepress}

include: Quality of life scores; Patient satisfaction audits; Treatment outcomes that focus on the patient; Research into improving patient outcomes; Hypotheses of interventions to improve outcomes; Short communications that illustrate improved outcomes; Case reports or series that show an improved patient experience; Patient journey descriptions or research. 